\title{
«LA FUENTE DEL DESENGAÑO»: \\ DE LAS NOCHES DE INVIERNO DE ESLAVA \\ A LA TERCERA DIANA DE TEJEDA ${ }^{1}$
}

\author{
Cristina Castillo Martínez \\ Universidad de Jaén \\ ccastill@ujaen.es
}

El ÚNICO DÍA DE LAS NOCHES DE INVIERNO

\begin{abstract}
on tres las noches de invierno en las que un grupo de caballeros italianos de aire español (Fabricio, Leonardo, Silvio y Albanio), a los que se sumará al final una dama (Camila), se entretienen con animados diálogos en los que surgen «preguntas de filosofía natural y moral, insertas en apacibles historias» ${ }^{2}$. Los temas son variados y los relatos abundantes, pero solo dos son contados a plena luz del día y ambos vinculados con el agua: Fabricio narra la historia de la pérdida del navío de Albanio, que les lleva a hablar sobre las propiedades y virtudes de algunas fuentes; y Leonardo le corresponde contando «cómo fue descubierta la Fuente del Desengaño» (libro I, capítulo II). De los posibles orígenes y de las características de esta última, como de todas o de la mayoría de las historias de las Noches de invierno, ha hablado la crítica: Perott (1915: 733-734); José y Prades (1949: 176-179); Formichi (1970: 221-223); Oroval (1978, 1982); Barella (1985: 555 y ss.). No obstante, aun quedan algunos aspectos por tratar, sobre todo en lo que se refiere a su influencia en otros textos. De ellos se intentará dar cuenta en las siguientes páginas.

Tras la citada disertación sobre las propiedades del agua, en la que se emplean argumentos extraídos de San Agustín, Mela, Aristóteles o Marco Polo, entre otros (Eslava 1986: 75-76), Leonardo toma la palabra para convertirse en narrador:
\end{abstract}

\footnotetext{
1 Este trabajo se inscribe en el marco del Proyecto I+D+i del MINECO La novela corta del siglo XVII (y II) (FFI2013-41264-P).

2 Dedicatoria a D. Miguel de Navarra y Mauleón.
} 
en pago de la desdichada historia que me habéis contado, os quiero declarar el orden que hubo en descubrir una fuente llamada del desengaño, la cual está en Siria, con una muy admirable virtud, y es que el hombre o mujer que en el agua de la dicha fuente se mira ve dentro a su lado la cosa que más ama, de manera que, si uno ama mucho a su mujer, la ve a su lado, como si presente la tuviese.

FABRICIO: Yo os doy mi palabra, señor Leonardo, que si os mirásedes en la fuente, no veríades a vuestra mujer a vuestro lado.

LeonARDo: Ni tampoco, si mi mujer se mirara, me viera al suyo. Mas dejando gracias aparte, prestadme oído, que es muy gustoso cuento (77-78).

Este extenso relato narra cómo el asedio de la ciudad de Palmerina (Siria) por parte del tirano Odenato obliga a Justino a separarse de su esposa Libia para ir a hacerle frente. En el combate es apresado y vendido a un mercader quien, cierto día, le envía al bosque a recoger leña. Absorto en sus pensamientos, pierde el camino y acaba encontrando una curiosa fuente en la que ve el reflejo de su amada.

Mientras tanto Libia, preocupada por Justino, del que no sabe nada desde hace un año, decide ir en su busca vestida de hombre. En su peregrinar encuentra la misma fuente y también, para su sorpresa, ve en la superficie del agua el rostro de su esposo; lo mismo que le sucede a un ciervo con su amada cierva, muerta por unos cazadores. Poco después llega a la corte de Odenato y entra a servir como paje de su hija Celinda, que se enamora de ella pensado que es un hombre. La única manera que encuentra Libia de sacarla de su error es conducirla hasta la fuente, así descubre que es una mujer y que su amado es Justino; pero cuando Celinda ve el rostro de este, se enamora perdidamente de él y ordena buscarlo, no sin antes encerrar a Libia en un calabozo. Una vez que Justino está en la corte, intenta seducirlo y, aunque él la rechaza, el rey los encuentra juntos y ordena encarcelarlo en la misma celda en que, casualmente, está Libia. Reunidos finalmente los esposos, deciden desengañar al rey haciendo que él y sus jueces se miren en la famosa fuente, poniendo al descubierto la verdad de sus respectivos amores.

Este interesantísimo relato está construido sobre la base de distintos motivos - buena parte de ellos de origen popular ${ }^{3}$ - . La trama gira en torno al elemento fundamental que es la fuente, abundantísimo en los libros de caballerías o en los de pastores como lugar de encuentro, testigo o desencadenante de nuevas aventuras. No menos frecuente será en leyendas y relatos de tipo folclórico, de las que tanto Fabricio como Leonardo dan ejemplos. Lo particular de esta fuente es que sus aguas son capaces de desvelar a quien se mira en ellas la persona que verdaderamente ama, pero para que esta virtud se ponga de manifiesto es preciso que antes se produzca la separación de los esposos, como sucede en las novelas de aventuras bizantinas. En este caso, Antonio de Eslava echa mano del conflicto bélico como

H200. Tests of truth; D1788.1. Magic results from contact with water (Thompson, 1975). 
excusa convincente y contextualiza la trama en Siria, en tiempos del tirano Odenato, información que, según advierte Formichi (1970: 221, n. 3) y matiza Barella en su edición (1986: 78, n. 43), procede de la Historia imperial y cesárea, en la cual en suma se contienen las vidas y hechos de todos los césares, emperadores de Roma, desde Julio César hasta el emperador Carlos quinto, de Pedro Mexía (Sevilla, Juan de León, 1545): «Digo pues que estaba en estos tiempos en las partes de Oriente, un excelente y sabio hombre llamado Odenato, que era príncipe y capitán de unas gentes llamados palmerinos, que es provincia de Siria, el cual, viendo la cosa revuelta, como cada uno de los otros, se quiso él hacer señor...» ${ }^{4}$.

Con la separación, la peripecia está servida, pues el amor que se profesan y sobre todo la esperanza que depositan en su reencuentro se aviva gracias al hallazgo de esta fuente que, ubicada en un lugar aislado del bosque, al que nunca ha accedido nadie y, por tanto, inmaculado, permite recordar a la persona amada dando sensación de realidad. Sin embargo, llama la atención que cuando Justino primero y Libia después se acercan a la fuente solo se diga que ven el retrato del otro sin que se haga alusión al suyo, como si su mente o su alma proyectara a través de los ojos la silueta de quien llevan en su corazón. Mientras que cuando se relata esta misma anécdota experimentada por Celinda, el rey o los jueces, se insiste en que aparecen las imágenes de ambos. La falta de concreción en el caso de los esposos bien podría deberse a un simple descuido del autor, que no ha matizado este particular (que sí advierte Leonardo antes de iniciar el relato), aunque también podría ser que conscientemente el autor haya querido subrayar que el amor de los protagonistas es mayor, hasta el punto de que su imagen devuelve la del otro al mirarse en una superficie reflectante, convirtiéndose en ejemplo de la transformación de los amantes ${ }^{5}$.

Eslava hace especial hincapié en la importancia de la mirada. Basta tan solo la vista, aunque sea un aparente reflejo, para enamorarse. Es lo que le sucede a Celinda, quien deja de amar a Libia cuando se entera de que es una mujer, para embelesarse por Justino, esposo de aquella, al que solo ha visto un instante y ni siquiera de

\footnotetext{
Cito por la edición de Amberes, Pedro Bellero (1578: 145).

Así es como lo ha entendido Serés: «Teóricamente, nada se le puede objetar: la constante recreación — cogitatio - de la imagen de la amada en la phantasia supone que dicha imagen ocupe, mediante los espíritus vitales y enteramente, su alma, o sea, su "hábito"; también implica que la imagen, en tanto que transportada por el vehiculum animae que son los espíritus, salga por dichos espíritus animales a través de los ojos y se refleje en el agua. (Recuérdese, y valga el inciso, que no otro deseo alberga la esposa del Cántico espiritual de San Juan de la Cruz cuando en la canción 12 afirma: " $\mathrm{O}$ christalina fuente, / si en esos tus semblantes plateados / formase de repente / los ojos deseados / que tengo en mis entrañas dibuxados!"; la esposa, a sabiendas que el "hábito de su alma" es la imagen del esposo — está dibujada en sus "entrañas" - se mira en el agua para comprobar si se ha transformado en aquel, para ver al esposo a través suyo)». (Serés 1996: 310-311)
} 
manera real. Y es que se trata de un amor de visu, a primera vista, que se hace factible en la medida en que la belleza física se considera trasunto de la universal:

La infanta Celinda, que admirada estaba del descubierto suceso, sintió por sus delicadas venas discurrir una helada sangre que iba enfriando su encendido y amoroso pecho; y así como vido en las claras aguas el dispuesto cuerpo y hermoso rostro de Justino, comenzó a pasar el amor que a Libio tenía en el desventurado Justino, con tanta impresión en el alma que de la sombra o, por mejor decir, imagen suya quedó enamorada y casi fuera de sentido, disimulando en lo exterior todo lo posible por respecto de la nueva criada (87).

Las propiedades mágicas de esta agua, que es el agua de la verdad, causan extrañeza en quienes se contemplan en ellas. De ahí que busquen a quienes aman a los dos lados de ese particular «espejo»: en carne y hueso junto a ellos, atrapados en la profundidad de la fuente o convertidos, a causa de la muerte, en sombra espectral. Este hecho resulta tan sorprendente que los propios protagonistas echan mano de la razón para intentar explicarlo:

Pues, cansado Justino de herir al viento con sus quejas sin que aun el eco quiera responder a ellas, como hombre doctado de buen entendimiento consideró una razón de filosofía o, por mejor decir, efecto de la pasión, y es que la cosa que verdaderamente está muy fija en la imaginativa obra tal efecto que representa a los ojos la cosa imaginada, y así que podría ser que su intensa imaginación hubiese obrado tal efecto (82).

De modo semejante, Libia se muestra aturdida y engañada. No puede entender que aparezca la imagen sin que esté Justino, al que llama a voces. Nada dice, sin embargo, de su propio reflejo, que ya no es el de sus dorados cabellos, que hubo de cortar «porque no fuesen espías de su disfrazado traje» (83), en un recurso abundantísimo en la narrativa del Siglo de Oro (recuérdese el caso de Felismena en la Diana de Montemayor) y, de modo especial, en el teatro durante el siglo XVII (Bravo-Villasante 1976). El equívoco, el juego de las apariencias, que solo la protagonista y el lector conocen, confiere interés e intensidad al relato, pero se trata de una verdad que al ser desvelada no tiene efectos dramáticos, sino prácticos: Celinda deja de amar a Libia/Libio y se enamora de Justino.

Para Libia, el traje de varón es el traje del disimulo y sobre todo de la libertad en cuanto que le permite huir de la violencia del tirano que «entraba en la mísera ciudad violando sin temor alguno las niñas y castas doncellas» (Eslava 1986: 83). La indumentaria la protege del peligro y le concede poder para asumir papeles, como el de paje, que en la vida real le están vedados por su condición femenina. Pero su propia identidad disimulada no parece ser un problema. Sí que le causa desasosiego la visión de su esposo y solo con la llegada de un ciervo, protagonista 
de una historia similar, logra entender que todo es fruto de un engaño. No podemos olvidar que este simbólico animal se relaciona con el amor tanto en la literatura tradicional como en la religiosa, pues aúna lo sensual y lo divino. Así, es muy frecuente la alusión al ciervo que enturbia las aguas, su presencia como animal herido en sentido real y figurado, o la alegoría cristiana que utiliza la figura del ciervo sediento que, al ir a calmar su sed, encuentra la verdad (Morales Blouin 1981: 159-164). Y Libia, «volviendo una y muchas veces como sedienta cierva a la clara fuente» (84) para buscar el sentido a tan extraño suceso, solo consigue encontrarlo cuando se contempla en el ciervo.

Eslava pone una serie de marcas en su relato que recupera en el diálogo que Fabricio y Leonardo entablan al final del capítulo. De ahí que incida en un primer momento en que Justino al asomarse ve la imagen de Libia «tan bella y hermosa cuanto en su imaginación estaba» (Eslava 1986: 81), justificando su existencia como una proyección de lo que ocupa su mente, tal vez su alma, capaz de crear con la imaginación hechos insólitos engañando a la vista, algo que se reitera en el episodio de Celinda, quien «mirando con mucho cuidado si vería su propia imagen al lado de su querido Libio, en lugar suyo vio a un mozo dispuesto y galán y hermoso, el cual era Justino, que estaba retratado en la mente de Libio» (86-87). Esta misma idea la rescatan los contertulios de la «cornice» una vez concluida la historia:

LeonARDo: [...] Hallo que es la causa que la clara y sutil agua desa fuente debe pasar por algún extraño minero y dél reciba tal virtud que, comunicada aquélla al agua, sea suficiente y actual a representar lo que en la cogitativa del que se mira en ella está impreso, de manera que con su fuerza engañe a la vista y le parezca que vee la cosa amada, porque una vehemente imaginación imprime en la cogitativa una idea de la cosa imaginada $(91)^{6}$.

Tradicionalmente se piensa que el agua, en cuanto superficie reflectante, es símbolo de la imaginación o de la conciencia, que puede reproducir imágenes del pasado y en algunas ocasiones incluso del futuro. En este sentido, el agua, como el espejo, dice la verdad, pues muestra a las personas y a los objetos tal y como

6 Véase la completísima nota de Julia Barella en su edición (Eslava 1986: 91-92, n. 69): «Sobre el poder de la imaginación en la realización de hechos portentosos o maravillosos, ya habló Plinio, Hist. Nat., VII, 9, [...] "también una vehemente imaginación imprime en la materia una idea de la cosa imaginada con que sale semejante a ella" (en el Lib. V 12). [...]. Fray Francisco de Osuna nos cuenta: "Has de saber que la imaginación hace mucho y conforma consigo lo que es engendrado, mayormente si está muy impresa en el pensamiento y en la representación..." (Norte de los Estados, Sevilla, 1531, fol. 63). En El Cortesano de Castiglione se explica cómo la visión de la amada queda en la memoria: "y aun con la fuerza de la imaginación se formará dentro de sí mismo aquella hermosura mucho más hermosa que en la verdad no será" (388-389). La misma idea en Diálogos de amor (t. II: 7), en la Silva de Mexía (Parte II, cap. VIII: 313-316) y en A. de Torquemada, op. cit., p. 123». 
son, despojándolos de prejuicios o máscaras y dejando el alma al descubierto. Se convierte, por tanto, en un intermediario entre el mundo visible y el invisible. De hecho, antiguamente los hombres pensaban que la proyección de su sombra sobre una superficie reflectante era su alma, lo que les hacía vulnerables frente a los demás (Frazer 1944: 230-235).

El problema adicional que se plantean los contertulios es si la vista puede o no ser engañada, con ideas tomadas de la Silva de varia lección de Pedro Mexía y con parlamentos copiados prácticamente de los Diálogos de amor de León Hebrero ${ }^{7}$ que a Fabricio le parecen «demasiada filosofía» (Eslava 1986: 93):

Sí puede, y muy fácilmente, aunque es el más excelente de todos los otros sentidos, porque los ojos no semejan a las otras partes del cuerpo, porque no son carnales, sino lúcidos y diáfanos, y parecen estrellas, y en hermosura exceden a todas las partes del cuerpo. Y el objecto de la vista es todo el mundo corpóreo, así el celestial como el inferior. Los otros sentidos sólo pueden comprehender parte del mundo inferior, y esto imperfectamente; y el medio de los otros sentidos es: o carne, como el tacto, o vapor, como en el olfato, o humedad, como en el sabor, o aire movedizo, como en el oído. Pero el medio de la vista es diáfano y lúcido, que es el aire alumbrado de la celestial luz, la cual excede en hermosura a todas las partes del mundo. Y, así, dice Aristóteles que la causa porque amamos más al sentido de la vista que a los otros sentidos es porque nos adquiere más cosas conocidas que todos los otros (92).

Y es que todo este saber aglutinado en tan poco espacio termina por romper con la fluidez del diálogo y con el propio sentido del mismo, pues no siempre desemboca en conclusiones lógicas. El debate sobre las propiedades de esta fuente, sobre lo que la imaginación puede formar y sobre la mirada se sustenta sobre ideas o fragmentos casi copiados de Plinio, Castiglione, León Hebreo o Mexía (Eslava 1986: 25-26; Formichi 1970: 169 y ss.). Es una clara muestra de la importancia que se sentía por aunar entretenimiento y saber a partir de las obras de otros autores, lo que en parte se apoya en el concepto de la «imitatio», reduciendo su originalidad a la selección de los materiales (Barella 1985: 515), o como señala Juana de José y Prades (1949: 167):

La originalidad del autor se reduce al mínimo más inexcusable. Si entresacamos del libro las imitaciones y plagios a Pedro Mexía, a Antonio de Guevara, a los libros de caballerías y a las leyendas leídas aquí o allá, apenas nos queda nada en las manos. Pero lo poquito que permanece tiene mucho sabor castizo, me refiero a esos cortos pasajes que Eslava emplea para pasar de un cuento a otro [...]. Claro está que el plagio no tenía en la época de Eslava — como es bien sabido— la tras-

\footnotetext{
Obra fundamental en la época, que Eslava copia en otros pasajes de su libro, como en la historia de «Los trabajos y cautiverios del rey Clodomiro y la Pastoral Arcadia» del capítulo séptimo (Barella 1985: 528-530).
} 
cendencia de hoy. En nuestro teatro clásico, y aun entre los primeros dramaturgos de la Edad de Oro, abundan las imitaciones de argumentos.

\section{«IL FONTE DELLA PROVA DEGLI LEALI AMANTI»}

Antonio de Eslava, gran conocedor de obras literarias y de erudición que reelabora total o parciamente en sus textos, parece que también tuvo un modelo sobre el que construir la historia de Libia y Justino. Se trata de la continuación italiana del Platir. Y es que los libros de caballerías castellanos se difundieron rápidamente por Italia en traducciones impulsadas por el editor Michele Tramezzino desde su imprenta en Venecia, con la colaboración de los traductores Pietro Lauro y Mambrino Roseo da Fabriano (Bognolo 2008, 2011a). Este último trasladó del castellano obras de Pedro Mexía o de Antonio de Guevara, además de varios libros de caballerías, algunos de los cuales continuó de forma creativa en italiano. Un ejemplo claro es este que citamos, cuyo título completo reza así: La seconda parte et aggiunta nouamente ritrouata al libro di Platir, ualoroso principe, figliuolo del gran Primaleone imperador di Grecia, tradotta nella lingua italiana, da gli annali antichi di Grecia, 1560 (Bognolo 2010, 2011b). Precisamente, en los capítulos 80-81 narra un episodio sobre «Il fonte della prova degli leali amanti», que pudo servir de modelo para el relato de Eslava. Así lo advirtieron José de Perott (1915: 733-734) y Juana de José y Prades. Esta última afirma que:

No tiene nada de extraño que Antonio de Eslava conociese este libro de caballerías italiano, puesto que entonces cualquier aficionado a las letras conocía este idioma, y es de suponer que cuando Eslava sitúa los diálogos en sus Noches de invierno en Venecia y la mayoría de las acciones relatadas en Italia, sería capaz de leer un libro en italiano, sobre todo en una época de tan estrechas relaciones con la Península vecina. Por otra parte, tampoco es difícil, dado el abrumador número de libros de caballerías que se imprimían en la época, que existiese una versión castellana (1949: 177).

En estas páginas se cuenta cómo Darnandro, en su camino hacia el monte Libeo, topa con una compañía de damas y caballeros que le invitan a unirse a ellos e ir al día siguiente a probar la aventura de la «fuente de los leales amadores», que, tal y como la describen, coincide con la de la fuente del desengaño:

Il fonte che io dico -disse la donzella-, è con tal arte fabricato, che specchiandosi in esso cavaliere che ami donna o donzella, quando l'ami di vero \& buono amore, \& del medesimo habbia la corrispondenza di lei, l'acqua che sempre di sua natura estua, $\&$ si inalza dal fonte, si quieta restando abonacciata $\&$ ferma $\&$ dentro specciandosi il cavaliere vi vede la propria effigie, cosi del naturale che par viva di colei che egli ama, cosi allegra o turbata come in quel punto si truova, se il cavaliere, che al fonte si affaccia non ha anco posto amore a donna o donzella alcuna \& che l'amore che 
col tempo ha dapigliare sia con santa \& buona intentione di matrimonio \& habbia da essere alla sua amata donna leale, fa il fonte il medesimo suo naturale effetto \& dentro vi vede la forma \& figura ritratta dal naturale di colei che ha da amare \& se avviene che quella che egli ama, o è per amare, non sia a lui, o non habbia da essere totalmente leale, vedrà lei con gli occhi bassi, como che se si vergognasse del fallo che è per fare o che ella fa al suo amante. Il medesimo effetto fa nella pruova che la donna voglia fare del suo amante $\&$ noi si amo qui ragunate per andare a prenderci piacere in questa pruova \& son sei giorni che dal nostro paese siamo per questo effetto partiti, ma si poco camino facciamo, il giorno che quel che habbiamo cavalcato in sei, potremo senza molto disagiarsi fare in due, perche ci andiamo trastullando come vedete (f. $303 r-v)^{8}$.

Este relato tiene las trazas típicas de la ordalía caballeresca que, sin embargo, se desdibuja en el texto de Eslava. De hecho, desde el epígrafe del capítulo 80 se habla de la fuente como de una prueba: «Che don Darnandro seguendo il camino del Regno del Monte Libeo trovo vicino a un fiume una compagnia di donne \& cavalieri che lo invitarono ad albergar quella notte con esso loro per veder provare la mattina seguente la avventura del fonte \& quel che gli avvenne» (f. 300). Se entiende como una prueba de su fidelidad, como tantas que aparecen en los libros de caballerías (Gracia 1991: 109) y que aderezan el relato con elementos mágicos. No obstante, y a pesar del encanto que de por sí reviste, está desprovisto del resto de motivos que componen la historia reelaborada por Eslava, como la separación de los esposos, el travestismo, la presencia del ciervo, la prisión, la anagnórisis o el desengaño del rey y los jueces, que parecen ser compendio de distintas tradiciones, historias y tópicos que conforman esta «artificiosa maraña» de la que habla Leonardo y que debió de ser del gusto de los lectores del XVII, ávidos de entretenimiento y de saber. No en vano la obra de Eslava se reeditó en multitud de ocasiones e incluso algunos de sus relatos adquirieron independencia, como este de Libia y Justino, que fue traducido al inglés por T. Roscoe (1832) y recopilado por F. C. Sáinz de Robles en su Cuentos viejos de la vieja España (Madrid: Aguilar, 1957) (Oroval 1978: 21-45). Lo que no se sabía hasta ahora es que, al menos, una reescritura aparece inserta en una novela pastoril.

\section{ReESCRItURA EN LA TERCERA DIANA}

Y así es. Dieciocho años después de la publicación de las Noches de invierno, apareció muy lejos de las prensas de Pedro Labayen en Pamplona, una obra firmada por Jerónimo de Tejeda - un escritor castellano que ejerció como profesor de español en París-, con el título de La Diana de Montemayor nuevamente compuesta por Jerónimo de Tejeda [...] (París, 1627), conocida como la Tercera

8 Transcribo a partir de la edición de Venecia, Lucio Spineda 1611 (Aggivnta alla historia del invitto cavalier Platir, [...] parte seconda [...]). 
Diana. Es decir, se trata de una de las diversas continuaciones que se hicieron de la gran obra iniciadora del género de los libros de pastores. Lo curioso es que el autor advierte ya desde el título que en sus páginas... se da fin a las historias de la Primera y de la Segunda parte, en alusión, respectivamente, a las obras de Jorge de Montemayor y de Alonso Pérez, pasando por alto de manera deliberada la Diana enamorada de Gil Polo (que sería, por orden de aparición, la tercera parte), pues de ella copia parcialmente su temática y muchos de sus poemas. No podemos hablar de reelaboración de materiales o de imitatio, sino de un caso claro de plagio, que, además, no se limita solo a la obra del valenciano. De hecho, prácticamente todas las composiciones poéticas insertas en sus páginas son fruto del expolio, especialmente de las rimas o de las comedias de Lope de Vega, aunque también ha tenido delante Los diez libros de la Fortuna de Amor de Antonio de Lofrasso y La Galatea de Cervantes (Avalle-Arce 1974: 132-135; Castillo Martínez: en prensa). No se quedan atrás, tampoco, los relatos que salpimientan el libro y de los que también intentó dar cuenta Avalle-Arce (1974: 131-132), tanto de los que califica de histórico-legendarios, como de los novelescos, inspirados algunos en comedias del Fénix quien, sin duda, fue uno de sus mayores modelos. No obstante, no pudo concretar la fuente de la historia de Tesandro y Rotilda [I, 240-263], que hoy podemos decir que concuerda precisamente con la de la fuente del desengaño. Si bien es cierto, Tejeda, como en otras ocasiones de su Tercera Diana, cambia el nombre de los personajes: Libia y Justino se llaman ahora Rotilda y Tesandro; el tirano Odenato, Otildo; y su hija Celinda se convertirá en Libia, nombre que coincide con el lugar en el que inicialmente viven los esposos (la Palmerina de la que habla Eslava).

Este relato se enmarca en un contexto pastoril y nada tiene que ver con la historia principal. Así, se dice: «la ninfa [Polidora] dijo a Felismena le hiciese placer de contar alguna historia para entretener los espíritus mientras pasaba la calurosa siesta» (Tejeda 1627: 240). Sin embargo, Felismena (por lo demás, perteneciente a un ámbito cortesano y no propiamente pastoril $)^{9}$ no dice que haya sido testigo de los hechos, ni que los haya escuchado contar, sino que los ha leído:

Acuérdome haber leído que en las partes de Libia hubo un gran rey llamado Otildo, el cual, viendo que una su ciudad, que cien leguas de corte distaba, llamada Astilea, se había metido so la obediencia de otro rey su vecino llamado Andromes y negádosela a él, invió un grueso ejército para reducirla a su obediencia. En esta ciudad residía una hermosa y noble dama llamada Rotilda, que con extremo amaba a un gallardo y noble mancebo, su esposo, llamado Tesandro (I, 240-241).

Los elementos fundamentales del relato coinciden en ambos. Si bien es cierto, la prosa de Eslava resulta más delicada, se detiene en algunos detalles y usa más

$9 \quad$ Acerca de la relación entre la novela pastoril y la novela corta, véase Castillo Martínez 2013. 
el estilo directo, lo que remarca el dramatismo de determinadas escenas, como la que tiene lugar antes de la despedida del matrimonio:

Querido y amado Justino, si el verdadero amor que entre los dos hay es una unión de voluntades, ¿qué es la causa que con tan poca ocasión te quieres apartar de mí, siendo mi voluntad diferente y contraria? No puedo atribuirlo a otra cosa sino que te habrás bañado en el Leteo, que es del olvido, [...] pues si es verdad, como dices, que eres mío, requiérote que no vayas; y si yo soy tuya, como es verdad, y no mía, llévame contigo, que te juro por la fe que te tengo dada de armarme de un pecto fuerte y de mostrar mis fuerzas más que varoniles, y puesta a tu lado pienso ser más valiente que ninguno de tus soldados; y esto será más por salvarte la vida que por libertar la patria (Eslava 1986: 79).

Estas palabras de Libia, expuestas a modo de epístola, quedan reducidas en la obra de Tejeda a esta sucinta narración:

el uno de estos escogidos fue Tesandro, el cual, la noche antes de salir al campo, se fue a reposar con su esposa, mas ella, como adivina de lo que la contraria fortuna aparejado le tenía, le rogó con abundancia de lágrimas que el día siguiente no saliesse al campo, poniéndole ante los ojos el gran peligro en que su persona iba y el en que ella quedaba, si el real ejército entrase por fuerza la ciudad. Y viendo que esto no podía alcanzar de su esposo, le rogó que, pues su resolución era de salir, la llevasse en su compañía para que, armada de un peto fuerte, a su lado le pudiesse hacer defensa o morir en su compañía (Tejeda 1627: 242-243).

De la misma manera que sucede con la extensa respuesta de Justino, que se resume en la obra pastoril en un "pero el valeroso Tesandro, pudiendo más con su corazón el honor que el ciego dios, lo mejor que supo consoló a su querida Rotilda y prometió volverla a ver, y la mañana venida se armó de lucientes y fuertes armas, y fue a la plaza de la ciudad en compañía de los que para salir al paso del ejército señalados estaban» (243).

El relato inserto en el libro de Tejeda mantiene el mismo orden en el desarrollo de los acontecimientos y en las intervenciones de los personajes que en el caso del de Eslava. Uno de los puntos cruciales es el hallazgo de la fuente por parte del esposo, convertido en un interesantísimo monólogo apoyado en una sucesión de preguntas retóricas paralelísticas en el texto del navarro, quien, por lo demás, incide en la importancia de la mirada, que da sentido a la teoría neoplatónica del amor de la que ya hemos hablado más arriba. Estas son las palabras de sorpresa, deseo y confusión de Justino, interpelando primero a la «vista», y después a la imagen de Libia, a la que cree real:

« Oh vista, verdadera amiga de mi descanso! ¿De qué sirve representarme la incomparable belleza del bien que adoro con interposición de frías y húmedas aguas, 
si guiada de tu natural lo haces para confortarte y apurarte en ellas? ¿No ves que los rayos de esa belleza penetrando la líquida y transparente agua bastan a encandilarte? Mas, ¡oh venturoso Justino!, ¿qué es eso que ves? ¿Duermes o estás despierto? ¿Qué es lo que miras? ¿No es ésta tu amada Libia? ¿No es ése su divino rostro? ¿No son ésas sus blancas y nevadas manos? ¿No son ésos sus coralinos labios? ¿No son esos ojos las dos estrellas fijas del cielo? ¿No es ése su alabastrino pecho? ¿No es ése su donaire y gala? ¿No es ella la que con semblante alegre me está mirando? $¡$ Oh hermosa Libia, dame parte de tu venida y asistencia en esta fuente! Dime, ¿no me respondes? Mas, ¿cómo ha de responder, si parece ser su sombra? Pues sombra de Libia sin su presencia es imposible, sino que ya la inexorable Átropos haya cortado el hilo de su vida y ande la fénix de su alma haciendo estas sombras interpuestas. Mas no es sombra ni imagen, sino su verdadera persona. Dime, hermosa Libia, ¿adónde estás? Si lo haces por burlarme, basta ya; mira que son costosas burlas del alma; déjame tocar siquiera los reflejos de tu rostro».

Pues poniendo por efecto su deseado intento, metió la mano dentro de las cristalinas aguas, $\mathrm{y}$, como alborotose el agua con la mano, por algún espacio de tiempo no se veían los rostros de ninguno dellos. Y, no entendiendo Justino la causa, entendía que Libia se había apartado de él, y así daba voces llamándole por la metad del bosque. Y como nadie se apiadaba de sus lastimosas quejas, tornó segunda vez a la fuente; y como el agua estuviese ya quieta, vio segunda vez la efigie de su amada Libia en ella y, obligado del amor, soltó las riendas al llanto, diciendo a Libia:

«Libia, ¿por qué permites, ingrata, que este esclavo tuyo sea de otro y padezca tal pena? Dime, hermosa Libia, ¿a dó te escondes? Que, si esta frígida fuente es tu morada, te juro por el eterno Caos de hacer aquí perpetua habitación contigo».

Pues, cansado Justino de herir al viento con sus quejas sin que aun el eco quiera responder por ellas [...] Y dando de mano a sus amorosas pasiones, cargó de la cortada leña sus machos, que parecía que estaban admirados de su tardanza; el cual en su largo camino con otras mil razones procuraba satisfacer a sus engañados ojos (Eslava 1986: 81-82).

El monólogo de Tesandro comienza también con la sorpresa, la imprecación a la esposa, el intento de constatación de la realidad sumergiendo la mano en el agua y su vuelta al camino perdido. Sin embargo, Tejeda se centra tan solo en el argumento, que parece conocer muy bien, pero se olvida del sentido y de la transcendencia que le otorga Eslava en lo que se refiere al modo en que se concibe el amor:

« ¡Oh, hermosa y amada esposa mía! ¿Qué es lo que decir me quieres, pues te me muestras en este húmedo elemento? Si es que quieres darme a entender que ya tu habitación no es en este mundo, sino en las cristalinas aguas, háblame para que procure seguirte con brevedad, pero no creo esto porque si tal fuera, no te me mostraras tan rozagante y contenta como te veo. Y así, si es que tú misma convertida en ninfa en estas cristalinas aguas tienes tu habitación, dímelo, para que no me ausente de tu agradable vista, y dame licencia para tocarte con la mano». 
Y diciendo esto, metió la mano en la fuente para tomar la de Rotilda, que la suya parecía alargar, pero como al entrar la mano en la fuente el agua se removiesse, la figura de Rotilda desapareció y Tesandro, viéndose ausente de su querida, comenzó a hacer un amargo llanto, y apartándose de la fuente e yendo de una parte a otra por el bosque daba voces y llamaba a su amada Rotilda; mas viendo que no le respondía, volviose a la fuente, a la cual llegado, como el agua se hubiese sosegado, volvió a ver en ella el retrato de su esposa junto con el suyo mismo y como hombre de buen entendimiento juzgó no ser aquello cosa natural, y así habiendo satisfecho su sed, volvió adonde sus pollinos dejado había y cargándolos se encaminó hacia la villa, llevando por todo el camino ocupada la memoria con lo que en la fuente visto había (Tejeda 1627: 246-247).

Los paralelismos son constantes, y se pueden seguir de manera clara, aunque no copie fragmentos exactos. Compárese el momento en que el ciervo se acerca a la fuente, que le sirve a la esposa como prueba de que lo que ha vivido es fruto del engaño:

Pues, como llegase el ciervo a la dicha fuente, luego se le representó en ella su perdida cierva, viendo la figura della en lo más hondo del agua, y, casi espantado, mostró tener un cierto modo de contento danto mil vueltas y corcovos de regocijo y contento; y con tener tan insaciable sed, temiendo dañar a su amada cierva, no hacía sino lamer el agua. Mas, como su natural istincto no se contentase con sólo eso, arrojose dentro de la clara fuente por alcanzar lo que sus engañados ojos le mostraban; mas, como se enturbiase el agua y su trabajo fuese en vano, salió de la dicha fuente y metiose dentro del espeso bosque. A todo lo cual estuvo la hermosa Libia muy atenta y, notando lo que había visto, dio en el engaño y virtud de las aguas, sirviendo de maestro el celoso ciervo (Eslava 1986: 84-85).

el ciervo, aunque sediento venía, como llegado a la fuente viese en el agua el retrato de una amada cierva que unos cazadores pocos días antes muerto le habían, olvidado de su natural necesidad, comenzó a delicadamente lamer el agua y viendo que la cierva no salía de la fuente, comenzó a brincar al brocal de la fuente, mas viendo que todas estas amorosas muestras no le eran de algún provecho, arrojose en la fuente, pero como en las aguas revueltas no viese su amada cierva, salió con gran ligereza de la fuente, y entrose con muestras de gran tristeza por la espesura del bosque, lo que visto por Rotilda conoció claro ser engaño del agua de la fuente lo que en ella visto había, y así determinó volver a su camino (Tejeda 1627: 252-253).

Tejeda mantiene pequeños detalles que no condicionan la historia, como los trescientos escudos que el mercader paga por el esposo. Es muy cercana también la narración del momento en que el rey descubre a Celinda y a Justino, por no hablar de ese episodio final, protagonizado por el rey y sus jueces, que tiene el cariz de un cuento y que supone el final de la narración. La fuente pone al descubierto 
la verdad escondida del rey, que no es otra sino su amor por «una tan fea y abominable mujer que causaba espanto a los que la veían, y ésta era la que al Rey traía hechizado» (Eslava:1986: 91) «El rey deseó mirarse y a su lado se vio una fea y abominable vieja toda cargada de instrumentos de hechicera» (Tejeda 1627: 261). En Eslava la vergüenza es la que mueve a pedir a los jueces que también se miren en aquellas aguas para que salgan a la luz sus «imperfecciones» y entre las de todos queden disimuladas:

y luego se vio al lado de un juez su vieja mujer digna de tal marido; y al lado de otro, que viudo era, una rolliza moza de cántaro, que parecía que con él quería agotar la fuente en venganza de su afrenta; y al lado de otro, muchísimos libros abiertos en quienes tenía puesta toda su afición; y al lado de otro, tres talegos abiertos llenos de doblones, como aquel que tenía puesto su amor y pensamiento en ellos y que muchas veces juzgaba por el dinero injustamente. De suerte que, hallándose cada uno culpado, se rieron unos de otros dándose entre ellos muchos y discretos motes y vejámenes. Así se disimuló con mucho secreto todo lo que habían visto.

Idea que no pareció entender o recordar Tejeda: «El rey mandó los jueces se mirasen en la fuente, lo que hecho por ellos, al lado de uno vieron a su mujer que estaba recibiendo sobornos de los pleiteantes; al del otro, cantidad de libros, todos cubiertos de polvo; y al del tercero, cantidad de diversos vinos y manjares» (261).

Donde sí que vuelve a haber coincidencia es en el final: «Y en la famosa Fuente del Desengaño hizo hacer un suntuoso edificio con perpetua guardia y clausura, para que nadie pudiese entrar sin su orden y licencia, y la intitularon la Fuente del Desengaño» (Eslava: 90-91), que Tejeda reelabora como «El rey, conociendo el engaño de la vieja que enhechizado le tenía, la desterró de su reino y puso pena a los jueces que no dijesen cosa de las en la fuente vistas y mandó hacer un suntuoso palacio en aquel bosque en el cual encerró la fuente que llamó del desengaño» (262-263); aunque, tras estas palabras, no se vuelve a hablar del tema, pues no es sino un relato inserto, diferente de la intención que le quiere dar Eslava como objeto de discusión, propia de los diálogos en los que da cabida a teorías e ideas de varios autores.

No sabemos con seguridad si en el escritorio de Tejeda, junto a los volúmenes de Gil Polo, Lope, Cervantes o Lofrasso, figuraba también el de Eslava abierto por el capítulo segundo del libro primero. Tal vez su lectura reciente o la de otro texto intermedio - hoy desconocido- que reprodujera en versión similar este relato guiara su pluma. Lo que está claro es que se trata de la misma historia, pues no faltan los elementos fundamentales. Sea como fuere, su pervivencia en su esquema más básico planteado por el autor de la segunda parte del Platir, reelaborado y nutrido por Eslava y reescrito por Tejeda, da muestra del gusto por unos motivos concretos, capaces de adaptarse al contexto caballeresco, cortesano 
o pastoril, y pone una vez más en evidencia la importancia de una literatura en pleno movimiento.

Recibido: 17/09/2014

Aceptado: 15/10/2014

\section{OBRAS CITADAS}

Aggiunta alla historia del invitto cavalier Platir, figliuolo del gran Primaleone Imperador de Greci, parte seconda: di nuouo ritrouata ne gli annali antichi di Grecia \& tradotta nella lingua italiana. Venecia: Lucio Spineda, 1611.

Avalle-Arce, Juan Bautista (1974). La novela pastoril española. Madrid: Istmo.

Barella Vigal, Julia (1985). «Las Noches de invierno de Antonio de Eslava: entre el folklore y la tradición erudita». Príncipe de Viana, 175, pp. 513-565.

Bognolo, Ana (2008). «Libros de caballerías en Italia». En Amadís de Gaula, 1508: quinientos años de libros de caballerías. Madrid: BNE-Sociedad Estatal de Conmemoraciones Culturales, pp. 333-342.

(2010). «Vida y obra de Mambrino Roseo da Fabriano, autor de libros de caballerías». eHumanista 16, pp. 77-98.

(2011a). «Libros de caballerías. Traducciones italianas». En Gran Enciclopedia Cervantina. Vol. VIII. Madrid, Castalia-Centro de Estudios Cervantinos, pp. 69736977.

(2011b). «Libros de caballerías. Continuaciones italianas». En Gran Enciclopedia Cervantina. Vol. VIII. Madrid, Castalia-Centro de Estudios Cervantinos, pp. 69776980.

Bravo-Villasante, Carmen (1976). La mujer vestida de hombre en el teatro español (siglos XVI-XVII). Madrid: Sociedad General Española de Librería.

CAstillo Martínez, Cristina (2013). «La novela pastoril y la novela corta: cruce de caminos». En Isabel Colón, David Caro, Clara Marías y Alberto Rodríguez (eds.), Los viajes de Pampinea: novella y novela española en los Siglos de Oro. Madrid: Sial/Prosa Barroca, pp. 225-236.

(en prensa). «Tras los pasos de La Diana de Jorge de Montemayor: continuaciones, imitaciones, plagio». En Continuaciones literarias y creación en España (siglos XIIIXVII). Madrid: Casa de Velázquez.

Eslava, Antonio de (1986). Noches de invierno. Julia Barella (ed.). Pamplona: Gobierno de Navarra (Institución Príncipe de Viana).

- (2013). Noches de invierno. Julia Barella (ed.). Madrid-Frankfurt: IberoamericanaVervuert.

Formichi, Giovanna (1970). «Narratori del Seicento: Le Noches de invierno di Antonio de Eslava». Lavori Ispanistici, 2, pp. 145-256.

Frazer, Jammes George (1944). La rama dorada. México: Fondo de Cultura Económica.

Gracia, Paloma (1991). «El "arco de los leales amadores", a propósito de algunas ordalías literarias». Revista de Literatura Medieval, 3, pp. 95-115.

José y Prades, Juana de (1949). «Las noches de invierno de Antonio de Eslava». Revista Bibliográfica y Documental, 3, pp. 163-196. 
Mata IndurÁin, Carlos (2003). «Sobre la admiratio en las Noches de invierno de Antonio de Eslava». Zangotzarra 7, pp. 91-115.

(2004). «Elementos fantásticos y maravillosos en las Noches de invierno (1609) de Antonio de Eslava». En Nicasio Salvador, Santiago López-Ríos y Esther Borrego (eds.), Fantasía y literatura en la Edad Media y los Siglos de Oro. Madrid/Frankfurt: Iberoamericana - Vervuert, pp. 259-282.

MenÉndez Pelayo, Marcelino (1961). Orígenes de la novela. Madrid: CSIC, vol. III, pp. 188-212.

MeXía, Pedro (1578). Historia imperial y cesárea en la qual en summa se contienen las vidas y hechos de todos los Césares, emperadores de Roma desde Julio César hasta el emperador Carlos Quinto. Amberes: Pedro Bellero.

Morales Blouin, Egla (1981). El ciervo y la fuente. Mito y folklore del agua en la lírica tradicional. Madrid: José Porrúa Turanzas.

Oroval MarTí, Víctor (1978). Aproximación a las Noches de invierno de A. Eslava. Valencia: Universidad. Tesis doctoral. (1982). «Narrativa y crítica literaria». Príncipe de Viana 166-167, pp. 1039-1048.

Perott, José de (1908). «Sobre las fuentes de algunos capítulos de las Noches de Invierno». Cultura española 12, pp. 1023-1029.

(1915), «Dos palabras más sobre las fuentes de las Noches de Invierno». Cultura española 15, pp. 733-734.

SERÉs, Guillermo (1996). La transformación de los amantes. Imágenes del amor de la Antigüedad al Siglo de Oro. Barcelona: Crítica.

TeJeDA, Jerónimo de (1627). La Diana de Monte-Mayor nuevamente compuesta por Hieronymo de Texeda [...] do se da fin à las historias de la Primera y Segunda parte [...] Tercera parte. París: a costa del autor.

Thompson, Stith (1975). Motif-index of Folk-Literature: a Classification of Narrative Elements in Folktales, Ballads, Myths, Fables, Medieval Romances, Exempla, Fabliaux, Jest-Books, and Local Legends. Bloomington: Indiana University Press, 6 vols. 


\section{政 \\ «LA Fuente del desengaño»: De las Noches de InVIERno de Eslava \\ a la Tercera Diana de Tejeda}

RESUMEN: El relato de «La fuente del desengaño», inserto en las Noches de invierno de Antonio de Eslava y posiblemente inspirado en la segunda parte del Platir, fue reelaborado, tiempo después, en un singular libro de pastores, el conocido como Tercera Diana de Jerónimo de Tejeda. En las siguientes páginas, se analizan los elementos que componen dicho relato para, más tarde, observar los modos en que ha sido reescrito, dando muestra clara de su efectividad estética.

Palabras Clave: Fuente, Reflejo, Noches de invierno, Tercera Diana, Antonio de Eslava, Jerónimo de Tejeda.

\section{«The Fountain of TRUth»: From Noches de InVIERno, by ESLAVA, to Tercera Diana, by Tejeda}

Aвstract: The story of «The Fountain of Truth», inserted in the Noches de invierno, by Antonio de Eslava, and inspired probably by the second part of Platir, was later reworked by Jerónimo de Tejeda in Tercera Diana, a singular pastoral romance. In the following pages, we analyze the elements of this story to see how it has been rewritten in order to demonstrate its success.

Keywords: Fountain, Reflection, Noches de invierno, Tercera Diana, Antonio de Eslava, Jerónimo de Tejeda. 
Evangelina Rodríguez Cuadros (Universitat de València)

Novela cortesana, novela barroca, novela corta: de la incertidumbre al canon .9

Mita Valvassori (Universidad de Los Lagos)

El modelo narrativo del Decamerón en la Edad de Oro: una vieja historia .21

Antonio Gargano (Università degli Studi di Napoli Federico II)

«Difficile est proprie communia dicere»: el género de la novella entre

Boccaccio y Cervantes

Guillermo Carrascón (Università degli Studi di Torino)

Apuntes para un estudio de la presencia de Bandello en la

novela corta del siglo XVII

Leonardo Coppola (Università degli Studi «G. d'Annunzio» di Chieti-Pescara)

La proyección de Straparola en la novela española del Siglo de Oro desde una perspectiva editorial

Mireia Aldomì García

Didactismo, género literario y lector en Giraldi Cinzio.

María Jesús Zamora (Universidad Autónoma de Madrid)

«...En tiempo menos discreto que el de agora, aunque de hombres más sabios, se

Ilamaban a las novelas cuentos». La novela corta y el cuento en el Siglo de Oro.....109

Marcial Rubio (Università degli Studi «G. d'Annunzio» di Chieti-Pescara)

La contribución de Cervantes a la novela barroca: la ejemplaridad. .125

PIERRe Darnis (Université Bordeaux Montaigne)

La fuerza de la sangre, La ilustre fregona $y$ Las dos doncellas: ¿tres tipos

folclóricos?

María Soledad ArRedondo (Universidad Complutense de Madrid)

De La gitanilla $a$ La sabia Flora malsabidilla. El género, el personaje

y el matrimonio

Antonella Gallo (Università degli Studi di Verona)

Fabulaciones en equívocos burlescos: la Chrónica del monstro imaginado (1615)

de Alonso de Ledesma y novela corta barroca

David GonZález Ramírez (Universidad de Málaga)

El filósofo del aldea (1625) de Baltasar Mateo Velázquez: recepción textual

e hipótesis autorial.

Jonathan BRAdBury (University of Exeter)

La narrativa breve en la miscelánea del siglo XVII 
Cristina Castillo Martínez (Universidad de Jaén)

«La fuente del desengaño»: de las Noches de invierno de Eslava a la Tercera

Diana de Tejeda.

María Zerari (Université Paris-Sorbonne, CLEA)

Furor in fabula: La cruel aragonesa de Castillo Solórzano (o de la dama monstruo).. 241

Giulia Giorgi (Università degli Studi di Ferrara)

Alonso de Castillo Solórzano reescritor de sí mismo: algunas notas sobre los

Escarmientos de amor moralizados y el Lisardo enamorado .257

Angela Fabris (Alpen-Adria-Universität Klagenfurt)

El diálogo con el público y los espacios reales y de maravilla en

Casos prodigiosos y cueva encantada de Juan de Piña .267

María Rocío LePe García (IES San Sebastián, Huelva)

La traducción inglesa de Hipólito y Aminta: una adaptación

con fines comerciales 281

Andrea Bresadola (Università degli Studi di Udine)

La novela española en la Italia del siglo XVII: el caso de Il Feniso

de Francisco de Quintana

José Teruel (Universidad Autónoma de Madrid)

El triunfo del Desengaño. Marco y desengaño postrero de la Parte segunda

del Sarao y entretenimiento honesto, de María de Zayas

Nieves Romero-Díaz (Mount Holyoke College)

Lecturas alternativas en la Novela del fin bueno en mal principio

de doña Ana Francisca Abarca de Bolea.

Shifra Armon (University of Florida)

Compromiso y distanciamiento en La Venus de Ferrara

de Mariana de Carvajal Saavedra

Mechthild Albert (Rheinische Friedrich-Wilhelms-Universität Bonn)

Las "noches": un subgénero novelístico en perspectiva comparada.... .365

Fernando Copello Jouanchin (Université du Maine, Le Mans)

El mueble en la novela corta del Siglo de Oro: algunas reflexiones

en torno a la cama

Ilaria Resta (Università del Salento):

De la novella al entremés pasando por la novela corta: reescrituras del cuento

La gara delle tre mogli del Cieco di Ferrara. 


\section{EDAD DE ORO}

Revista de Filología Hispánica XXXIII

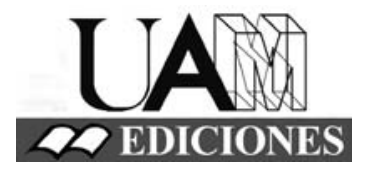




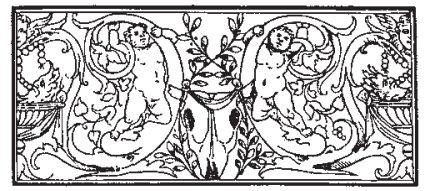

\section{Edad de Oro. Revista de Filología Hispánica}

ISSN: 0212-0429

Dirección:

Teodosio Fernández

Secretaría y edición:

José Ramón Trujillo

Coordinador del volumen XXXIII:

Rafael Bonilla Cerezo

Comité científico internacional:

Carlos Alvar (Univ. de Ginebra)

Ignacio Arellano (Univ. de Navarra)

Javier Blasco (Univ. de Valladolid)

Alberto Blecua (UAB)

Jean Canavaggio (Univ. de París X)

Laura Dolfi (Univ. de Turín)

Aurora Egido (Univ. de Zaragoza)

Víctor García de la Concha (RAE)

Luciano García Lorenzo (CSIC)

Joaquín González Cuenca (Univ. de Castilla-

La Mancha)

Agustín de La Granja (Univ. de Granada)

Begoña López Bueno (Univ. de Sevilla)

Michel Moner (Univ. de Toulouse III)

Joan Oleza (Univ. de Valencia)

Alfonso Rey (Univ. de Santiago)

Lina Rodríguez Cacho (Univ. de Salamanca)

Leonardo Romero Tobar (Univ. de Zaragoza)

Aldo Ruffinatto (Univ. de Turín)

Lía Schwartz (City University of New York)
Redacción y admisión de originales:

Teodosio Fernández

Edad de Oro

Departamento de Filología Española

Universidad Autónoma de Madrid

28049 Madrid (España)

Tfno.: +0034 914974090

correo: teodosio.fernandez@uam.es

Distribución, suscripción y venta:

Servicio de Publicaciones de la UAM

Universidad Autónoma de Madrid

28049 Madrid (España)

Intercambio de publicaciones:

Biblioteca de la Facultad de Filosofía y

Letras (UAM)

Universidad Autónoma de Madrid

28049 Madrid (España)

Han colaborado en este volumen:

Departamento de Filología Española (UAM)

Facultad de Filosofía y Letras (UAM)

Proyecto I+D FFI2013-41264-P La novela

corta del siglo XVII: estudio y edición (y II)

Edad de Oro se recoge en las siguientes bases de datos: SCOPUS, MLA Database, HLAS, Latindex, PIO-Periodical Content Index, ISOC, Dialnet, MIAR, ERIH, DICE, Sumaris CBUC, Ulrich's. Se encuentra evaluada en CIRC: A; INRECH: primer cuartil, posición 6 de 50; MIAR difusión ICDS live: 9.977; SCImago Journal \& Country Rank: H Index 2, SJR 0,101, Q4; RESH índice de impacto: 0.162; ERIH: A INT1; Carhus Plus+: B. 